Tropical Journal of Pharmaceutical Research May 2017; 16 (5): 1045-1049

ISSN: $1596-5996$ (print); 1596-9827 (electronic)

(C) Pharmacotherapy Group, Faculty of Pharmacy, University of Benin, Benin City, 300001 Nigeria.

All rights reserved.

Available online at http://www.tjpr.org

Original Research Article

http://dx.doi.org/10.4314/tjpr.v16i5.11

\title{
Healing effect of Sanguisorba officinalis L extract on second-degree burns in rats
}

\author{
Xin Le and You-fen Fan* \\ Department of Burns, Ningbo No. 2 Hospital, Ningbo, 315010, Zhejiang, China
}

*For correspondence: Email: lexin494133@163.com; Tel: +86 0574-83870964

Sent for review: 7 January 2017

Revised accepted: 3 April 2017

\begin{abstract}
Purpose: To investigate the healing effect of Sanguisorba officinalis L. extract (SOLE) on seconddegree burns in rats.

Methods: Male Sprague Dawley rats, weighing 200 - $220 \mathrm{~g}$, were subjected to deep second-degree skin burns by electrical scald instrument. The animals were divided into three groups as follows: (1) second-degree burns model (control), (2) burns model treated with $1 \%$ silver sulfadiazine (SSD), and (3) burns model treated with SOLE. On days 3, 7 and 14, following administration of drug/extract, the wound area and histopathological changes of rat epidermis were evaluated in all the groups. Minimum inhibitory concentration (MIC) of SOLE on Staphylococcus aureus, Pseudomonas aeruginosa and Escherichia coli was also assessed separately.

Results: On day 14, the mean wound area of SOLE treatment group $\left(0.22 \pm 0.05 \mathrm{~cm}^{2}\right)$ was significantly smaller than that of control rats $\left(2.67 \pm 0.18 \mathrm{~cm}^{2}, p<0.01\right)$. Histological data indicate that inflammatory cells of burnt rats disappeared and were replaced by new granulation tissue by day 14 for the group treated with SOLE. The antibacterial results revealed that the MIC of SOLE for Staphylococcus aureus, Pseudomonas aeruginosa and Escherichia coli was $3.5,14.0$ and $7.0 \mathrm{mg} \cdot \mathrm{mL}^{-1}$, respectively.

Conclusion: Sanguisorba officinalis $L$. appears to be an effective medicinal herb for the treatment of second-degree burns.
\end{abstract}

Keywords: Sanguisorba officinalis, Burns, Healing, Antibacterial, Silver sulfadiazine

Tropical Journal of Pharmaceutical Research is indexed by Science Citation Index (SciSearch), Scopus, International Pharmaceutical Abstract, Chemical Abstracts, Embase, Index Copernicus, EBSCO, African Index Medicus, JournalSeek, Journal Citation Reports/Science Edition, Directory of Open Access Journals (DOAJ), African Journal Online, Bioline International, Open-J-Gate and Pharmacy Abstracts

\section{INTRODUCTION}

Every year, millions of people suffer major disability or even death from burns caused by hot water, flame and boiling oil. People suffer from burns due to domestic and industrial accidents, which along with enormous cost of treatment, cause mortality and considerable morbidity [1]. According to the World Health Organization (WHO), there were 300,000 deaths worldwide due to burns in 2012, with $96 \%$ of these deaths occurring in developing countries [2]. Burn wounds are one of the health problems in modern societies associated with irreparable harms for patients and their families [3].

At present, silver sulfadiazine is the most used topical treatment for burn injury due to its potent anti-microbial efficacy. However, it was found that silver showed some problems after prolonged use and had systemic complications such as neutropenia, methemoglobinemia and renal toxicity [4]. Therefore, finding more efficient agents with fewer side effects for treatment of burns has always been a concern of researchers.

Sanguisorba officinalis $L$, a traditional Chinese 
medicinal herb, is widely distributed in Southern China. The root of Sanguisorba officinalis $L$. has been used in treatment of inflammation, infection, jaundice, skin burns and hyperlipemia in China and Japan [5]. Several studies have evaluated the antioxidant capacity of Sanguisorba officinalis L.extract $[6,7]$ and anti-inflammatory activities such as the inhibition of NF-kB [8]. In this study, Sanguisorba officinalis $L$. extract was investigated on the healing activity on burn wounds in rats.

\section{EXPERIMENTAL}

\section{Materials}

Herbal samples of Sanguisorba officinalis $L$. were collected from Bozhou City, Anhui Province in China in May 2014. Taxonomic identification of the plant was performed by Prof. Xia $\mathrm{Hu}$ of Zhejiang University of Chinese Medicine in China. A voucher specimen (no. SOLE 201405023) was deposited in the Department of Pharmacy, Ningbo No. 2 Hospital, China for future reference.

Sanguisorba officinalis $L$. sample was placed in a round bottom flask with $70 \%$ ethanol $(1: 8, \mathrm{w} / \mathrm{v})$ for reflux extraction at $80{ }^{\circ} \mathrm{C}$. It was extracted twice for two hours each. Then the ethanol was removed by rotary evaporator, and the remaining solution was concentrated into $200 \mathrm{~mL}$ volume by evaporating as the extract. The working concentration of SOLE was equivalent to 100 $\mathrm{mg} \cdot \mathrm{mL}^{-1}$ (extract weight/final volume).

\section{Animals and model preparation}

Male SD rats weighing 200 - $220 \mathrm{~g}$ were obtained from Zhejiang Center for Disease Control and Prevention, Hangzhou, Zhejiang. The rats had free access to feed which were purchased form Guangxi Jiangda Feed Co. Ltd, China, and were allowed to acclimatise for at least one week before use. The animal experiment was approved by the Animal Care and Use Committee of Ningbo No. 2 Hospital (approval ref no. 20120908) and was carried out in compliance with Directive 2010/63/EU on the handling of animals used for scientific purposes [9].

After the back hair was removed by a clipper, 20 $\%$ ethyl carbamate solution was used for anesthetizing the rats by injection. The top of electrical scald instrument (Changhai Hospital of Second Military Medical University, China) was pressed on the back skin with a certain force for $15 \mathrm{~s}$ at $75^{\circ} \mathrm{C}$. In this way, the second-degree burn model was prepared in rats.

\section{Experimental groups and treatments}

All rats were randomly divided into three groups of 35 rats in each: second-degree burn model group, SSD-treated group and SOLE-treated group. All animals of model, SSD-treated and SOLE-treated groups received the deep seconddegree burn. SSD cream (1\%, w/w) was used as standard drug.

In a preliminary study, the dose-response properties of SOLE and silver sulfadiazine were examined to determine the optimal dose, and the most effective in the wound healing was $0.3 \mathrm{~g}$ SSD or $1 \mathrm{~mL}$ SOLE per wound (data not shown). $1 \mathrm{~mL}$ SOLE or $0.3 \mathrm{~g}$ of SSD was applied slowly with cotton bud to the burn wound area and extended slightly outside the wound area to ensure inclusion of the wound edges.

Treatments were repeated twice daily for 14 days. The first application was done directly after the wound injury. Control group did not receive any treatment for 14 days. The wound remained exposed after the treatment.

\section{Measurement of mean wound area}

On days 3, 7 and 14 following treatment, average wound areas of control, SSD and SOLE group rats were measured respectively. The wounds were photographed with a digital camera in order to calculate the wound surface areas (WSA) with the software AUTOCAD. The change in wound surface area in a given day (WSA day-x) was expressed as percent of the wound area on the second day $\left(\mathrm{WSA}_{\text {day-2}}\right.$ ) using $\mathrm{Eq} 1$.

WSA $(\%)=\left\{\left(W_{2}-W_{x}\right) / W_{2}\right\} 100$

where $W_{2}$ and $W_{x}$ are the mean wound surface area on days 2 and $x$, respectively.

\section{Histological study}

Wound skin tissue samples were taken by a scalpel from the control, SSD and SOLE groups on days 7 and 14 for histological observation. The skin tissues were fixed with $10 \%$ formalin. After fixation, samples were embedded in paraffin, cut into $3 \mathrm{~mm}$ frozen sections with a cryostat microtome, then stained with hematoxylin eosin reagent. Collagen fiber, inflammatory cell, blood vessel and granulation tissue of the skin tissues were examined under a microscope.

\section{Antibacterial test}

Use agar dilution to determine the minimum 
inhibitory concentrations (MIC) of SOLE on Escherichia coli (ATCC23276), Staphyloccocus aureus (ATCC26542) and Pseudomonas aeruginosa (ATCC25338). The three bacteria were all diluted to $1.5 \times 10^{5} \mathrm{CFU} \cdot \mathrm{mL}^{-1}$ with $0.9 \%$ sodium chloride solution. The experiment was repeated three times to determine MIC.

\section{Statistical analysis}

Values are expressed as means \pm SEM. Multiple group comparisons were performed using oneway analysis of variance (ANOVA) with the SPSS 18.0 followed by Dunnett's test to detect intergroup differences. $P<0.05$ was considered significant in all cases.

\section{RESULTS}

\section{Wound healing}

The macroscopic appearance of the seconddegree burn wound, treated with SSD and SOLE are shown in Figure 1. The wound area of rats treated with SSD or SOLE decreased progressively. The wounds treated with SOLE healed more quickly than those of control group. The average wound area of SOLE and SSD treatment groups resolved more quickly than control groups by day $14(p<0.01)$, suggesting that both treatment probably accelerated the process of wound healing hence there was significant reduction in the wound area. Meanwhile, the average wound area of rats with SSD treatment was smaller than control groups on day $14(p<0.01)$.

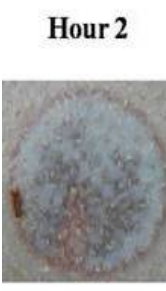

$$
\text { Day } 3
$$

Day 7

Day 14
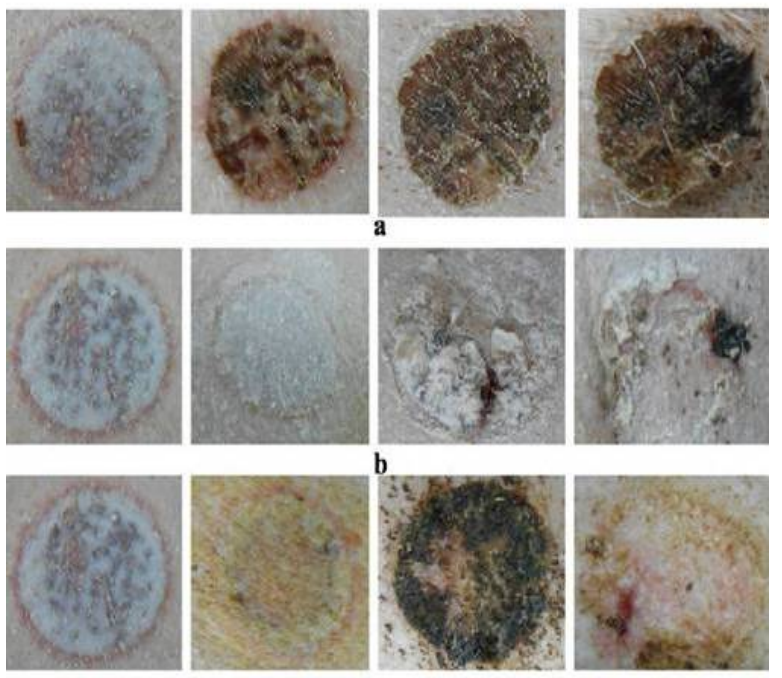

Figure 1: Photographs of macroscopic appearance of wound repair. (a) Control, (b) SSD, and (c) SOLE at $2^{\text {nd }}$ hour, Days 3, 7 and 14 respectively

\section{Histological characteristics}

A second-degree burn showed muscular and adipose tissues, of which there were neither dermis nor epidermis and infection was absent. Histological findings on the wounded skin, treated with SSD and SOLE on days 7 and 14 are shown in Figure 2. On day 0, collagen fiber was necrotic, inflammatory cell infiltrated below striated muscles and vascular engorgement and necrosis were seen in the burn skin of model rats. On day 7 , there was severe infiltration of inflammatory cells and some fibroblast and granulation tissues were found in the burnt skin of control rats.
Day 7
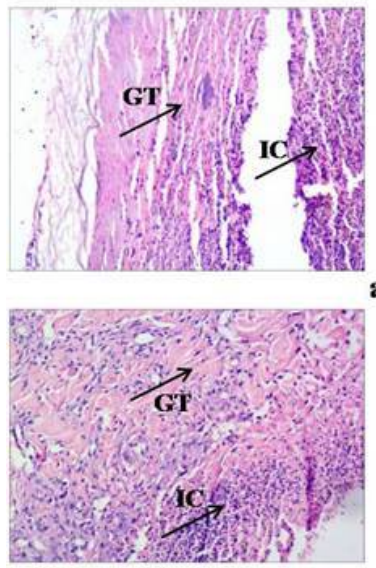

b

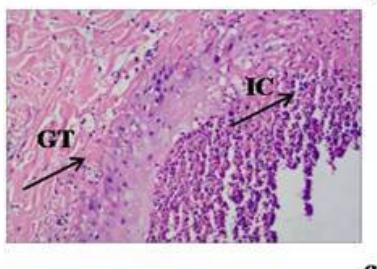

Day 14
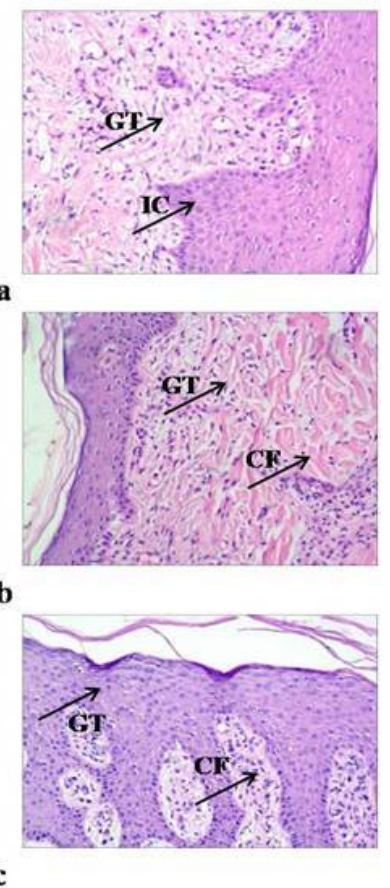

Figure 2: Skin pathomorphology of burns rats. (a) model, (b) SSD treatment, and (c) SOLE treatment on Day 7 and Day 14 respectively $(100 \mathrm{x})$. Key: IC: inflammatory cell, GT: granulation tissues, CF: collagen fibers

Meanwhile, burnt skin of rats treated with SSD or SOLE showed a significant reduction of inflammatory cell and many fibroblast and granulation tissues appeared. By day 14, inflammatory cells were still seen and some fibroblast and granulation tissue had begun to grow in the burnt skin of the control rats. However, there were fleshy buds constituted with blood vessels and fibroblasts, inflammatory cells disappeared and were replaced by new granulation tissue, collagen fibers and epithelialization progressed very quickly in rats treated with SSD or SOLE. 


\section{Antibacterial activity}

The MIC of SOLE on Staphyloccocus aureus, Pseudomonas aeruginosa and Escherichia coli were $3.5,14.0$ and $7.0 \mathrm{mg} \cdot \mathrm{mL}^{-1}$, respectively.

\section{DISCUSSION}

Thermal burn injury is still a major cause of death and disability in the world and its healing process is a challenge in modern medicine. Burns on human body may be treated by different methods depending on the extent and severity of the burn. SSD is bactericidal on a wide variety of bacteria, so it is commonly used to treat infections of second and third degree burns. Recent studies revealed that SSD ointment has positive effects on the proliferation of fibroblasts which are the main source of collagen and fibronectin [10]. However, current reports suggest that silverbased products show side effects and researchers are making efforts to seek better topical antimicrobial products [11].

In the treatment of burns, a key aim is to control bacterial infection. The common and main bacteria isolated from clinical burn patients were Staphylococcus aureus, Pseudomonas aeruginosa and Escherichia coli. SSD is the most used topical treatment for burns due to its antimicrobial efficacy. However, it causes systemic complications such as neutropenia, methaemoglobinemia and renal toxicity [3]. Traditional Chinese medicine has the advantage of inhibiting bacterial growth with minimum side effect. It was reported that gallic acid showed strong antibacterial activity [12], and it is one of the main constituents of Terminalia chebula Retz. Therefore, SOLE inhibits bacterial infection in burns.

In recent years, there has been a growing interest in alternative medicines and natural medicinal products for the local treatment of wounds due to the high costs of traditional drug treatments [13]. Skin integrity is restored by a physiological process aimed at repairing the damaged tissues. The healing process proceeds in four phases: hemostasis, inflammation, proliferation and remodeling [14]. The time required for complete healing of deep seconddegree burns, without the application of specific therapeutic agents, can be three to six weeks or more, and these burns will leave a scar tissue that may undergo hypertrophy and contract itself [15]. In this study, SOLE accelerated the scab of deep-degree burn wound and prevented infection effectively.
Burn wounds treated with SOLE recovered well by day 14 . However, the wounds of control group still showed severe inflammatory cell infiltration and no complete healing.

\section{CONCLUSION}

The findings of this study indicate that Sanguisorba officinalis $L$. extract accelerates healing of second-degree burns in rats. It also has strong antibacterial activity, and thus has the potential to be developed as a therapy for burns treatment.

\section{DECLARATIONS}

\section{Acknowledgement}

The authors express their thanks to their colleagues in Department of Pathology of Ningbo No. 2 Hospital for support.

\section{Conflict of Interest}

No conflict of interest associated with this work.

\section{Contribution of Authors}

The authors declare that this work was done by the authors named in this article and all liabilities pertaining to claims relating to the content of this article will be borne by them.

\section{Open Access}

This is an Open Access article that uses a funding model which does not charge readers or their institutions for access and distributed under the terms of the Creative Commons Attribution License (http://creativecommons.org/licenses/by/ 4.0) and the Budapest Open Access Initiative (http://www.budapestopenaccessinitiative.org/rea d), which permit unrestricted use, distribution, and reproduction in any medium, provided the original work is properly credited.

\section{REFERENCES}

1. Nacer Khodja A, Mahlous M, Tahtat D. Evaluation of healing activity of PVA/chitosan hydrogels on deep second degree burn: pharmacological and toxicological tests. Burns 2013; 39: 98-104.

2. J Kopp, GY Wang, RE Horch. Ancient traditional Chinese medicine in burn treatment: a historical review. Burns 2003; 29: 473-478.

3. LS Edelman. Social and economic factors associated with the risk of burn injury. Burns 2007; 33: 958-965. 
4. N Shanmugasundaram, TS Uma, TS Ramyaa Lakshmi, Mary Babu. Efficiency of controlled topical delivery of silver sulfadiazine in infected burn wounds. $J$ Biomed Mater Res A 2009; 89: 472-482.

5. Peng $W$, Qin R, Li X. Botany, phytochemistry, pharmacology, and potential application of Sanguisorba officinalis L.: A review. J Ethnopharmacol 2010; 146: 713-720.

6. Masaki H, Sakaki S, Atsumi T, Sakurai H. Active-oxygen scavenging activity of plant extracts. Biol Pharm Bull 1995; 18: 162-166.

7. Hsu CY, Chan YP, Chang J. Antioxidant activity of extract from Sanguisorba officinalis L. Biol Res 2009; 37: 13-20.

8. Eve EB, Phillip G, James LH, Louise W, Diane KH. Topical anti-inflammatory activity of Sanguisorba officinalis $L$. extract in the TPA model of mouse ear inflammation. J Inflamm 2005; 5: 2-7.

9. European Commission [homepage on the internet]. Directive 2010/63/EU on the protection of animals used for scientific purposes [cited 2013 Jan 16]. Available from:http://ec.europa.eu/environment/chemicals/lab_ani mals/legislation_en.htm.
10. Coelho JM, Antoniolli AB, Nunes eSilva D. Effects of silver sulfadiazine, ipêroxo (tabebuia avellanedae) extract and barbatimão (stryphnodendron adstringens) extract on cutaneous wound healing in rats. Rev Col Bras Cir 2010; 37: 45-51.

11. Burd A, Kwok CH, Hung SC, Chan HS, Gu H, Lam WK, Huang L. A comparative study of the cytotoxicity of silver-based dressings in monolayer cell, tissue explant, and animal models. Wound Repair Regen 2007; 15: 94104.

12. Aijuan L, Jixiang C, Weiming Z, Tao J, Xiaohua Z, Qianqun $G$. Antibacterial activity of gallic acid from the flowers of Rosa chinensis Jacq. against fish pathogens. Aquaculture Res 2007; 38: 1110-1112.

13. Lee JA, Jeong HJ, Park HJ, Jeon S, Hong SU. Acupuncture accelerates wound healing in burnedinjured mice. Burns 2011; 37: 117-125.

14. Pazyar N, Yaghoobi R, Rafiee E, Mehrabian A, Feily A. Skin wound healing and phytomedicine: a review. Skin Pharmacol Physiol. 2014; 27: 303-310.

15. Johnson RM, Richard R. Partial-thickness burns: identification and management. Adv Skin Wound Care 2003; 16: 178-187. 